\title{
Front Matter: Volume 12066
}

, "Front Matter: Volume 12066," Proc. SPIE 12066, AOPC 2021: Micro-optics and MOEMS, 1206601 (24 November 2021); doi: 10.1117/12.2622810

SPIE. Event: Applied Optics and Photonics China 2021, 2021, Beijing, China 


\title{
PROCEEDINGS OF SPIE
}

\section{AOPC 2021: Micro-optics and MOEMS}

\author{
Yuelin Wang \\ Huikai Xie \\ Yun-Feng Xiao \\ Editors
}

\section{0-22 June 2021 \\ Beijing, China}

Organized by

University of Electronic Science and Technology of China (China)

Science and Technology on Low-light-level Night Vision Laboratory (China)

Science and Technology on Electro-Optical Information Security Control (China)

Nano-Optoelectronics Laboratory, Department of Electronic Engineering, Tsinghua University (China)

Sponsored by

Chinese Society for Optical Engineering (China)

Published by

SPIE

\section{Volume 12066}


The papers in this volume were part of the technical conference cited on the cover and title page. Papers were selected and subject to review by the editors and conference program committee. Some conference presentations may not be available for publication. Additional papers and presentation recordings may be available online in the SPIE Digital Library at SPIEDigitalLibrary.org.

The papers reflect the work and thoughts of the authors and are published herein as submitted. The publisher is not responsible for the validity of the information or for any outcomes resulting from reliance thereon.

Please use the following format to cite material from these proceedings:

Author(s), "Title of Paper," in AOPC 2021: Micro-optics and MOEMS, edited by Yuelin Wang, Huikai Xie, Yun-Feng Xiao, Proc. of SPIE 12066, Seven-digit Article CID Number (DD/MM/YYYY); (DOI URL).

ISSN: 0277-786X

ISSN: 1996-756X (electronic)

ISBN: 9781510650077

ISBN: 9781510650084 (electronic)

Published by

SPIE

P.O. Box 10, Bellingham, Washington 98227-0010 USA

Telephone +1 3606763290 (Pacific Time)

SPIE.org

Copyright (C) 2021 Society of Photo-Optical Instrumentation Engineers (SPIE).

Copying of material in this book for internal or personal use, or for the internal or personal use of specific clients, beyond the fair use provisions granted by the U.S. Copyright Law is authorized by SPIE subject to payment of fees. To obtain permission to use and share articles in this volume, visit Copyright Clearance Center at copyright.com. Other copying for republication, resale, advertising or promotion, or any form of systematic or multiple reproduction of any material in this book is prohibited except with permission in writing from the publisher.

Printed in the United States of America by Curran Associates, Inc., under license from SPIE.

Publication of record for individual papers is online in the SPIE Digital Library.

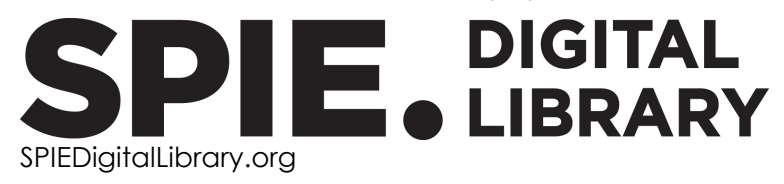

Paper Numbering: A unique citation identifier (CID) number is assigned to each article in the Proceedings of SPIE at the time of publication. Utilization of CIDs allows articles to be fully citable as soon as they are published online, and connects the same identifier to all online and print versions of the publication. SPIE uses a seven-digit CID article numbering system structured as follows:

- The first five digits correspond to the SPIE volume number.

- The last two digits indicate publication order within the volume using a Base 36 numbering system employing both numerals and letters. These two-number sets start with 00, 01, 02, 03, 04, $05,06,07,08,09,0 A, 0 B \ldots$.. 0Z, followed by 10-1Z, 20-2Z, etc. The CID Number appears on each page of the manuscript. 


\section{Contents}

PHOTONIC MEMS, THZ MEMS AND METAMATERIALS

1206602 Research on application of laser in interferometric fiber optic gyroscope for excellent scale factor stability [12066-3]

1206603 Highly sensitive fiber Bragg grating sensor interrogation system based on a Fourier domain mode-locked optoelectronic oscillator [12066-4]

1206604 Analysis of nonlinear crosstalk suppression in weakly multi-core fiber based on coupled-power theory [12066-5]

1206605 Micromachined double-layer chiral metasurface [12066-6]

$1206606 \quad$ 10Gb/s single user hybrid fiber-FSO-fiber system based on optical CDMA [12066-7]

$1206607 \quad$ Electrically reconfigurable terahertz digital metasurface based on vanadium dioxide phase transition [12066-8]

1206608 A micro optical sensor based on twin-core fiber [12066-9]

1206609 Inverse nanotapers and lensed fibers for highly efficient coupling [12066-10]

12066 OA A compact and low power SLM system for augmented reality applications [12066-11]

12066 OB The effect of central frequency of ultrasonic transducer on the glucose detection based on photoacoustic spectroscopy [12066-12]

12066 OC A high-frequency angular vibration calibration system based on phase modulated laser interferometer technique [12066-13]

12066 OD Design and fabrication of silicon-based optical phased array [12066-14]

12066 OE Research on the construction method of the displacement field for a star sensor bracket based on fiber Bragg grating strain monitoring [12066-15]

12066 OF Design and optimization of a compact polarizer on the surface plasmon polaritons based SOI waveguide [12066-21]

12066 OG Thermal resistance and optical performance of SMD LEDs with traditional package and chip scale package [12066-22]

$12066 \mathrm{OH}$ Experimental analysis for recorded data frame of amplitude-modulation coaxial holographic data storage [12066-27] 
12066 Ol Crosstalk-sensitive RCSA with dedicated path protection in spatial division multiplexing elastic optical networks [12066-28]

12066 OJ Solution to engineering problems of silicon-optical switches: reliability of co-package [12066-29]

12066 OK Recognition of sound vibration by DCNN based on $\varphi$-OTDR system [12066-30]

12066 OL Ultra-compact dual-mode silicon power splitter using sub wavelength gratings couplers [12066-31]

12066 OM DMD-based intelligent light distribution technology of LED headlamp [12066-32]

12066 ON A single sideband phase modulated radio over fiber link with spurious-free dynamic range enhancement [12066-33]

1206600 Compact mode-insensitive ring resonator based on SWG coupler and Euler bends [12066-36]

12066 OP Automatic bias control of a silicon photonics dual parallel Mach-Zehnder optical modulator [12066-37]

12066 OQ Design of ultra-wide-angle beam splitter [12066-38]

12066 OR Improved structural and electrical properties of non-polar a-plane p-AIGaN epi-layers with pulsed mass flow supply technique [12066-40]

12066 OS A cost-cutting solution for coherent optical device packaging: wafer-level combine test of optical and analog chips [12066-41]

12066 OT Research on microstructure of nickel disc and optical disc for long-life holographic storage by two-time electroplate [12066-45]

12066 OU Application of structured illumination microscopy in fast and accurate measurement of complex-surface and steep-edge [12066-46]

12066 OV Bayesian optimization of photonic nanojets generated by multilayer dielectric structures [12066-47]

12066 OW Enhanced efficiency and stability of perovskite solar cells with ultra-thin $\mathrm{Al}_{2} \mathrm{O}_{3} \mathrm{Contact}$ interlayer via low temperature atomic layer deposition [12066-48]

12066 0X Computer-generated hologram with complete depth information of reflection and refraction using ray tracing rendering [12066-49]

12066 OY Viewing-angle enhanced three-dimensional light-field display based on optical-digital joint optimization algorithm [12066-50]

12066 OZ Calculating method for circular interference fringe of Mach-Zehnder optical system [12066-51]

1206610 Design of lighting system for head-mounted display device [12066-52] 
1206611 Research on influencing factors of GNSS-R ocean remote sensing satellite efficiency index [12066-54]

1206612 Depth-based fusion network for human attention prediction in 3D light field [12066-55]

1206613 Performance evaluation of 3D light field display based on air traffic control task [12066-56]

1206614 Thermal sensitivity of the birefringence of photonic-bandgap fiber [12066-57]

1206615 Real-time multi-view background matting for 3D light field video [12066-58]

$1206616 \quad$ Inverse design of multifunctional metamaterial based on modified direct binary search algorithm [12066-59]

1206617 Dynamical characterization of viewing zone in a super multi-view 3D display based on eyetracking [12066-60]

1206618 Long-distance gesture detection based on deep learning for 3D spatial interaction [12066-61]

1206619 Exploiting LDPC coding to improve data reliability for phase modulated holographic storage [12066-63]

12066 1A Study on Kalman dynamic prediction and feedback parameter optimization of laser tracking system [12066-64]

12066 1B Design and error analysis of Gabor-type diffractive lens [12066-65]

12066 1C A chip-level 400G integrated coherent receiver optical-electronic testing system [12066-66]

12066 1D Highly balanced $2 \times 2$ multimode interferometers by optimizing the coupling of the taper fan-out [12066-67]

12066 IE Research on single fiber imaging technology under fiber deformation [12066-68]

$12066 \mathrm{IF}$ Study on the life test of optical information storage materials [12066-69]

$120661 G$ Controlled fabrication of graphene layers and devices based on plasma etching [12066-70]

12066 1H Generalized adaptively biased optical OFDM for optical wireless communications [12066-71]

$1206611 \quad$ Performance of fixed-scale MIMO UOWC systems using OOK and spatial multiplexing under misalignment effect [12066-72]

12066 1J A flat panel light field 3D display with high resolution for a single user [12066-73]

12066 1K Machine learning accelerated holographic near-eye display system based on three-step diffraction [12066-74] 
12066 IL Optical characteristics investigation on H-PDLC flexible curved radius grating [12066-76]

12066 1M Simultaneous enhancement of radial resolution and side lobe suppression of tubular hyperlens via introducing a nano-gap layer [12066-77]

12066 iN Diffusion kinetics investigations of the dual monomer system in the photopolymer holographic material [12066-79]

1206610 On BER performance for misaligned underwater wireless MISO laser links [12066-81]

12066 1P Angle of arrival of underwater wireless optical communications [12066-82]

$120661 Q \quad$ Rapid local modulation of $\mathrm{VO}_{2}$ phase transition by graphene heater [12066-83] 